\title{
Score-rating system influence on the formation of general professional competence of students in technical universities
}

\author{
Galiya Igtisamova*, and Doniyor Nosirov \\ Ufa State Petroleum Technological University, Branch of the University in the City of Oktyabrsky, 54a, Devonskaya St., \\ Oktyabrsky, Republic of Bashkortostan, 452607, Russia
}

\begin{abstract}
The Ministry of Education and Science of the Russian Federation has established a score-rating system to assess the achievement quality within academic disciplines. The word "rating" is a foreignlanguage term, literal translation into Russian means "assessment". The second meaning of the word "rating" is a numerical measure; it characterizes performance of a student, pupil, etc., during a certain period of training, usually by the 20-point scale, or 100-point scale. This article highlights the history of formation and implementation of a score-rating system into the curriculum. Due to development of advanced technologies, there is a need for training highly qualified personnel to solve increasingly complex problems in professional activities. In our opinion, pedagogical assessment of student's knowledge in the form of score-rating system is a key role for preparing highly qualified personnel. The authors study processes of training skilled professionals in the course of academic education in technical universities of our country.

Key words: score-rating system (SRS), competence, student, progress, credit, rating, factor.
\end{abstract}

\section{Introduction}

Higher education institutions of the Russian Federation use a score-rating system to assess the quality of students' achievements within academic disciplines. The English word "rating" means "assessment"; it is a numerical characteristic of understanding and mastering something. As history shows, in a normative way, a score-rating system was formed in the early 1930s, and later by the 1960 s the authorities started to implement it gradually. It should be noted that in the last century the score-rating system existed in the form of examinations and examinational tests. The history of the sore-rating system is associated with the research conducted by the specialists of the city of Astrakhan. The study conducted at Astrakhan Technical University of the Fishing Industry and later named "Astrakhan" showed that in the current education system according to the evaluation of exams and tests on the examination passing date, as well as the results of qualitative or non-qualitative responses to teachers' questions the majority of students learn, memorize or learn by heart, and then forget after a while all the studied. After reviewing the results of the study, teachers across the country asked the question: "Is our current assessment of the quality of knowledge and achievements of students right?" And, then they initiated the heated discussion on simplification of the control and achievement system.

These discussions resulted in teachers' conclusion that it was necessary to focus on the questions asked at the defense of practical, laboratory work and to implement "Colloquiums" as mini exams during the semester, and the correctness of the results and answered questions should be evaluated with points (from 0 to 5). During the semester, students had to earn points, the most active students could get automatic assessment, i.e. without passing the exam, get an assessment for active studying the discipline. Many teachers unanimously supported that idea and considered it necessary to make above-mentioned amendments to the education system. As we know from the course of history, that was period of authoritarian rule, the state treated all the issues and assumed all the obligations; thus, to introduce those innovations in the education system was very difficult, as it took a long time to treat and justify those issues by the state. It is important to consider the evolution of the term "competence"; depending on time its definition was understood differently. We present the following stages in the evolution of "competence" definition:

$>$ From 1950-1970 - the term was defined as "professionally important qualities»

$>$ From 1970-1990 - the term was defined as "adaptation to rapidly changing conditions and requirements of the activity, ability to transfer acquired skills to other areas of activity"

After 1990 - the term was defined as the broadest concept "human readiness for effective work".

\section{Purpose of the research}

The purpose of our research is: to study the score-rating system influence on the formation of the competence of

\footnotetext{
* Corresponding author: Igtisamova_galiy@mail.ru
} 
students in technical universities, on determining factors affecting the competence of students and considering the creative potential influence on the formation of the competence of students.

\section{Results and discussions}

Today, this system, proposed by Soviet teachers, has been significantly improved and fully implemented in the education scheme of the Russian Federation as a "Score-Rating system" (abbreviated SRS). The word "rating" is a key one in the implemented system.

As we mentioned above, "rating" is a foreign language term, which is literally translated into Russian as "assessment" [1]. The second meaning of the word "rating" - is a numerical criterion characterizing the performance of a student, pupil, etc., during a certain period of training, usually represented in the 20-point scale, or 100 -point scale. In view of its totality, rating is divided into various types that regulate the order of study of discipline and evaluation of student's achievements in it:

- rating on the discipline, considering the student's performance on the exam (test);

- overall average indicative semester rating, showing the student's academic performance in the disciplines studied in a semester;

- final rating for the system of related disciplines studied during a certain period;

- integral rating for a specific period of study, showing performance over a period of time.

For the efficiency, as we mentioned above the ratings are calculated on a 100-point scale. Many technical universities of our country use the following scale in order to translate that rating into a four-point rating scale:

- 0 to 60 is unsatisfactory, which means a definite "two";

- from 61 to 77 - satisfactory, i.e. "three";

- 78 to 90 - good, "four".;

- from 91 to 100 - excellent, solid "five".

Competence translated from Latin means a range of issues in which a person is well-informed, has knowledge and experience. A competent in a certain area individual possesses relevant knowledge and abilities, allowing him to reasonably judge in a specifically certain area and effectively act in it [2].

In our case, under the competence of a graduate student of oil technical university, we mean a specialist who can solve the following problems in the oil and gas industry:

- elaboration of geological and technical measures for the development of new oil and gas deposits [3];

- design of technology and methods for formation study;

- development of equipment and technology for drilling oil and gas wells;

- making management decisions in the development of fields and for the efficiency of oil and gas production process.
It is possible to list a range of other narrow-profile problems, for example, description of descent-lifting operations by means of linear differential equations of mathematical physics [4], the solution of which is the responsibility of every student of the course. During the training of highly qualified specialists in oil technical universities of our country, students study a number of special disciplines with a strong focus on them: development and operation of oil and gas fields [5], drilling oil and gas wells, borehole oil production, and operation of oil and gas wells, hydrodynamic investigations of wells (well testing) [6], major repairs of wells (workover), oil recovery enhancement, a complication of oil production, collection and preparation of oil and gas, etc. The degree of development and studying these disciplines by students is evaluated according to a score-rating system, a positive or satisfactory outcome of which significantly has both positive and negative effects on the future career of the student. One must also consider that studied disciplines and the ability of students to apply their theoretical knowledge in practice are the key factors in making the above decisions.

The general professional competence of graduates of oil technical universities consists of 3 main components:

- Cognitive, knowledge-related and ways of obtaining it.

- Functional, i.e. ready to act professionally in any situation.

- Personal or value-based and ethical, which is the motives and values of the individual, manifested in the process of formation of competence, as shown in figure 1 .

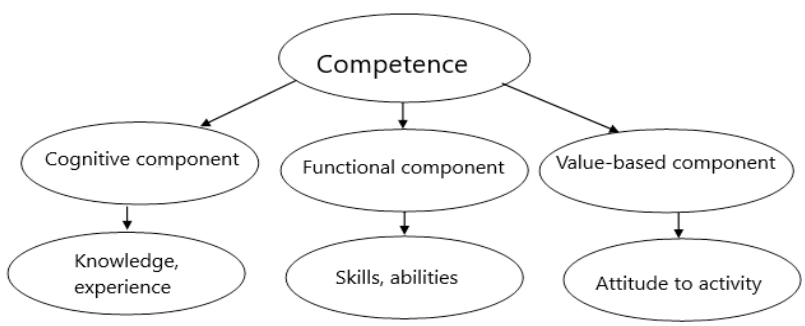

Fig.1 Competence structure

Let us take a closer look at the cognitive component of "Competence" and describe levels of competence formation.

As we have previously pointed out, cognitive component is associated with the initial school knowledge of the student, as well as with the method of mastering a particular material by the student. There is a so-called concept "Bloom's Taxonomy". Bloom's taxonomy is a set of three hierarchical models used to classify educational learning objectives by levels of complexity and specificity. Thus, Bloom identified 6 levels of the hierarchical structure of cognitive (perceptive) environment:
* Knowledge.
* Understanding.
* Application.
* Analysis.
* Synthesis. 
* Assessment.

For a better understanding of each of the above levels of hierarchical structure of cognitive environment, we will give a definition of them.

Knowledge. This category refers to memorization and reproduction of the material studied - from specific facts to a holistic theory.

Understanding. An indicator of understanding can be a transformation of the material from one form to another, interpretation of the material, assumption of the future course of events.

Application. This category indicates the ability to use the studied material in specific conditions and new situations.

Analysis. This category refers to the ability to distinguish the material into components so that the structure is clear.

Synthesis. This category refers to the ability to combine elements to get a whole that has novelty.

Assessment. This category refers to the ability to assess the value of the material.

Description of levels of competence formation:

Threshold. Mandatory for all graduate students upon completion of the educational program of higher professional education. The student at this level reproduces the terms, basic concepts, knows methods and procedures for determining physical and mechanical properties.

Advanced. Exceeding the minimum characteristics of the formation of competence for a graduate. The student at this level can identify relationship between the structure and properties, applies the laws to prove a point of view. He/she evaluates significance of the experimental data and experiment errors.

High. Maximum possible expression of competence, it is important as a quality guide for self-improvement. $\mathrm{He} / \mathrm{she}$ elaborates and proposes a plan for development of a research (research project), forms conclusions, evaluates the relevance of findings and data. He/she assesses scientific and applied significance of his/her development.

Several factors affect a student's competence, regardless of how he /she studies or studied. "Factor" is the cause, the acting force of any process, which determines its nature or individual features. The environment of influence on the student in the learning process is considered factors. Factors that have a positive impact on the formation of general professional competence of students are divided into 3 groups:

- the first group includes factors related to psychology of a student, or rather, the student's interest in the profession, interest in developing activities, selfimprovement;

- the second group includes socio-economic factors, i.e. socio-economic conditions; material well-being of the family, a region of residence;

- the third group includes pedagogical factors, i.e. organization of the educational process of the university; involvement of students into research work; educational and industrial practice.

We believe that: the ability to apply the acquired knowledge gained in the process of studying at the university, as well as the ability to transfer ideas and methods from one science to another will be the key to successful training of highly qualified specialists in future professional activities. A graduate who mastered professional skills perfectly can be competitive in the labor market, and tolerance with in-depth knowledge that allows application of professional skills will help to achieve higher quantitative and qualitative indicators [7].

Solution of the main problems in the oil and gas industry, especially in our days, considering improved technology and methods, there is a need for highly qualified specialists who are able to creatively address complex problems of professional activity.

Creative competence of the student is a condition of student's creativity manifestation (compare English. "Creativity"), which literally means the level of creative talent [8]. Conditions of students' creative abilities manifestation are:

- available general intellectual abilities;

- ability and skills above the average level;

- dedication to the task;

- certain life factors called circumstances.

In the modern world there are more and more trends to consider creative competence of the student not as a process and even as an activity, but as a characteristic of the individual, lifestyle, way of dealing with the world. The word "creativity" covers a wide range of different skills that a student must have. Creative skills are needed to change the concepts of tasks and to quickly perceive real problems [9]. In most cases, the solution to a problem is associated with "finding alternative solutions". This implies that it is necessary to apply the skills of creativity by the student, each student must be aware of what creative abilities he/she has. That is why formation of creative potential of the student must begin at the initial stage of training, starting from the first or second course year. At the initial stage of academic training in the university a large number of hours are devoted to disciplines of the humanities and social sciences, so it is possible to create the most favorable conditions for formation of a creative approach to educational activities, ability to think freely, to defend one's own point of view, to find creative ways to solving problem situations [10]. In this regard, the problem of creativity of an individual, his/her creative abilities and creative potential is of importance.

Every student who dreams of an interesting and prestigious job should realize that in modern society there is a demand for creative, active individuals who are able to repeatedly change their profile of training, quickly adapt to the future profession and be able to apply their knowledge obtained at the university in various fields of professional activity. In order to enable the future engineer to meet all the requirements of society, modern universities need to shift the emphasis in the learning process from accumulation of ready-made knowledge, skills and abilities to "formation of an individual, who owns the technology of creative work, and is able to create something new and be personally responsible for it" (G.V. Lavrentiev). In our opinion, the list of components that will help young professionals to find their place in society and become popular includes: 
- ability to make quick decisions on various tasks in non-standard situations;

- to solve problems in a non-standard way;

- to act bravely and confidently;

- ability to realize their individuality and uniqueness.

The integration of competence building and acmeological approaches is important for the pedagogical system of vocational training of students in technical universities focused on self-development of a competitive individual in the labor market.

Each of the above approaches has its own conceptual framework and technological component. Orientation towards formation of basic professional, creative competencies develops students' desire for the highest professional achievements, that stimulates processes of development and self-development of professional creative competence.

At the present time, in the process of hiring a graduate student, employers focus their attention on the average score obtained by him/her in training, and only then get acquainted with personal achievements of the student in the learning process:

- involvement in scientific activity of the University research work, participation in various conferences and International competitions;

- taking part in the public life of the University.

\section{Conclusion}

In our study, we found out the score-rating system influence on the formation of competence of students in technical universities, identified the factors affecting their competence, and considered the creativity impact on the formation of competence of students. It should be considered that the score-rating system plays an important role in the formation of general professional competence of students in technical universities, it has both positive and negative impact on the psychology of the student, on his/her motivation in the study of disciplines. Based on the above considerations, we conclude that the score-rating system is a key element in the formation of students' motivation in the further study of a particular discipline, as well as a link in the formation of interpersonal relations between the teacher and student.

\section{References}

1. R. Soden, Teaching Problem Solving in Vocational Education (London: Routledge, 1994)

2. M. Claijre, Assessing the Effectiveness of ProblemBased Learning in Higher Education: Lessons from the Literature, Academic Exchange Quarterly, 5(1) (2001)

3. V.V. Mukhametshin, V.E. Andreev, G.S. Dubinsky, Sh.Kh. Sultanov, R.T. Akhmetov, The usage of principles of system geological-technological forecasting in the justification of the recovery methods, SOCAR Proc., 3, 46-51 (2016). DOI: 10.5510/OGP20160300288
4. Oct. C. Chin, Through Problem-Based Learning: Pedagogy and Practice, J. of Professional Issues in Engineering Education and Practice (1997)

5. G.R. Igtisamova, D.Sh. Nosirov, Peculiarities of problem-solving at studying well drilling with the use of linear differential equations with constant coefficients, Advances in Engineering Research (AER) (Int. Conf. "Actual issues of mechanical engineering” (AIME 2018)), 157, pp. 211-214 (2018). DOI: 10.2991/aime-18.2018.41

6. L.S.M. Yong, A studey a creativity and its correlates amonog form 4 pupils (Universiti Malaya, 1986)

7. E.A. Mukhtasarova, F.G. Safin, State of modern Russian youth tolerance, European Proc. of Social and Behavioural Sci. (RPTSS 2018 - Int. Conf. on research paradigms transformation in social sci.), 50, pp. 206-213 (2018). DOI: 10.15405/epsbs.2018.12.26

8. K.T. Tyncherov, F.A. Ikhsanova, M.V. Selivanova, Ranking objects by the main component method and highlighting the most informative object parameters, Radioengineering, 9, 185-192 (2018). DOI: 10.18127/j00338486-201809-30

9. K.T. Tyncherov, N.I. Chervyakov, M.V. Selivanova, I.A. Kalmykov, Method of increasing the reliability of telemetric well information transmitted by the wireless communication channel, Bull. of the Tomsk Polytechnic University, Geo Assets Engineering, 329(3), 36-43 (2018)

10. R.T. Akhmetov, V.V. Mukhametshin, A.V. Andreev, Sh.Kh. Sultanov, Some Testing Results of Productive Strata Wettability Index Forecasting Technique, SOCAR Proc., 4, pp. 83-87 (2017). DOI: $10.5510 /$ OGP20170400334 